\title{
Endoscopic therapy using an endoscopic variceal ligation for minute cancer of the esophagogastric junction complicated with esophageal varices: a case report
}

\author{
Tomoyuki Akiyama1', Yasunobu Abe1, Hiroshi lida1', Hiroki Endo', Kunihiro Hosono1', Kyoko Yoneda1, \\ Hirokazu Takahashi', Masahiko Inamori*1', Akihide Ryo², Shoji Yamanaka2, Yoshiaki Inayama² and Atsushi Nakajima'
}

\begin{abstract}
Introduction: Standard endoscopic mucosal resection or endoscopic submucosal dissection is a procedure for patients with minute cancers, complicated with esophageal varices that puts them at high risk of bleeding.

Case presentation: We present the case of a 77-year-old Japanese man with alcoholic cirrhosis who underwent a routine endoscopy examination as a screening procedure for esophageal varices and was incidentally diagnosed as having minute cancer of the esophagogastric junction with esophageal varices. Endoscopic ultrasonography findings suggested that the minute cancer was a non-invasive carcinoma (carcinoma in situ) and a $2 \mathrm{~mm}$ in diameter blood vessel, feeding the esophageal varices, pierced the lesion. Following the examination, we carried out endoscopic treatment of the minute cancer and esophageal varices. Endoscopic variceal ligation was performed using a pneumoactivated device (Sumitomo Bakelite, Tokyo, Japan). Two years after the treatment, during the follow-up endoscopic examination on the patient, recurrence of carcinoma was not detected endoscopically or histologically.
\end{abstract}

Conclusion: Endoscopic therapy using an endoscopic variceal ligation device for minute cancer of the esophagogastric junction, complicated with esophageal varices, may be an acceptable and easily applicable method.

\section{Introduction}

Minute cancer is a gastric cancer lesion of less than $5 \mathrm{~mm}$ in its maximum diameter, with tumor cells confined to the mucosa. Lymph node metastases, meanwhile, are extremely rare [1,2]. These characteristics of minute cancer provide the basis for using endoscopic therapy as a curative treatment [3]. In this report, we describe endoscopic therapy using an endoscopic variceal ligation (EVL) device for minute cancer complicated with esophageal varices.

\section{Case presentation}

A 77-year-old Japanese man with alcoholic cirrhosis had been undergoing a follow-up laboratory examination every month for three years. He had been undergoing

* Correspondence: inamorim@med.yokohama-cu.ac.jp

${ }^{1}$ Gastroenterology Division, Yokohama City University School of Medicine, Japan

Full list of author information is available at the end of the article imaging studies such as ultrasonography and computed tomography every month as screening procedures for hepatocellular carcinoma, and endoscopic examination every year to monitor esophageal varices. During one such routine examination, he was diagnosed as having minute cancer of the esophagogastric junction (EGJ) (Figure 1) based on the histological examination of the biopsy specimen (Figure 2) and esophageal varices (Figure 3). One month later, he was referred to our institution for endoscopic ultrasonography (EUS) evaluation (Olympus UM2000, Olympus Optical Company, Tokyo, Japan) and endoscopic therapy. The ultrasonography findings showed that the minute cancer was a noninvasive carcinoma (carcinoma in situ) and a blood vessel, $2 \mathrm{~mm}$ in diameter feeding the esophageal varices, pierced the lesion (Figure 4).

Following the EUS examination, we carried out endoscopic treatment of the minute cancer and esophageal 


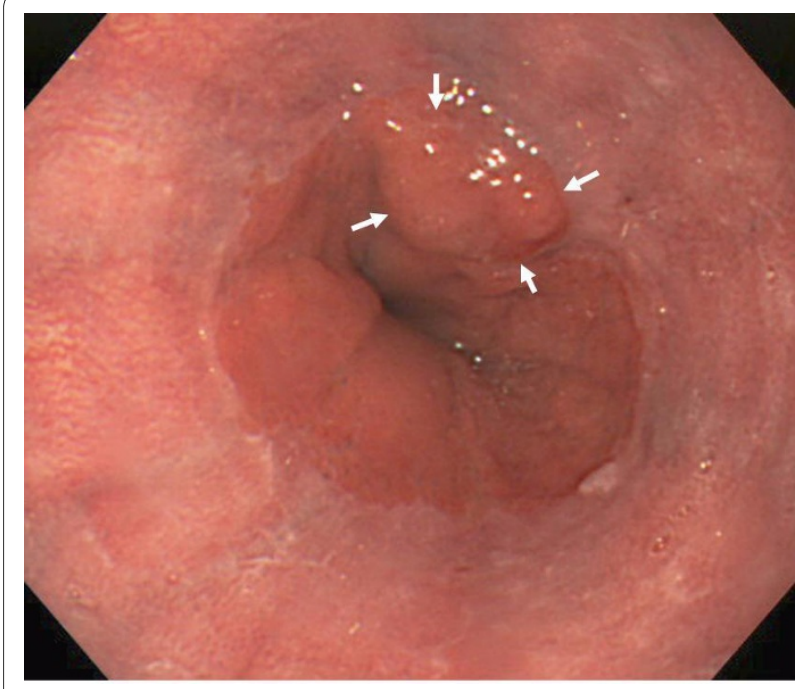

Figure 1 Minute cancer of the esophagogastric junction. White arrows indicate the minute cancer.

varices. The endoscope (GIF-Q200, Olympus Optical Co., Tokyo, Japan) was preloaded with an overtube, which was passed into the oropharynx over the already introduced endoscope. The tip of the endoscope was loaded with a pneumatic EVL device (Sumitomo Bakelite, Tokyo, Japan). Under full endoscopic suction, the minute cancer was tightly packed inside the cap of the endoscope, and the tripwire was pulled, creating an artificial polyp that included the lesion. After confirmation that the electrocautery markings were contained in the ligated band, resection was not performed for the lesion. EVL was successively done for the esophageal varices in three places. All EVL bands were placed in the esophagus and EGJ.

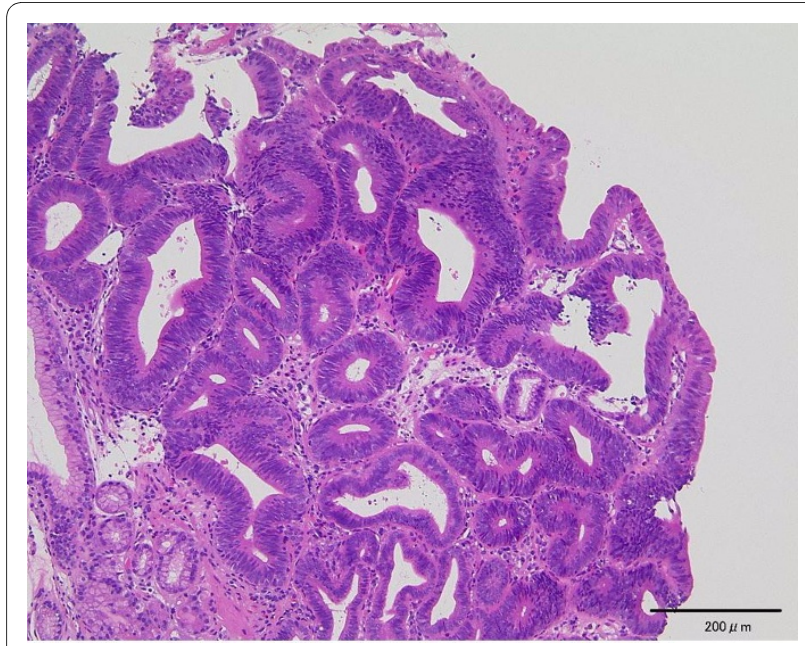

Figure 2 Histological examination of the biopsy specimen showed well-differentiated adenocarcinoma (hematoxylin and eosin staining, original magnification $\times 100$ )

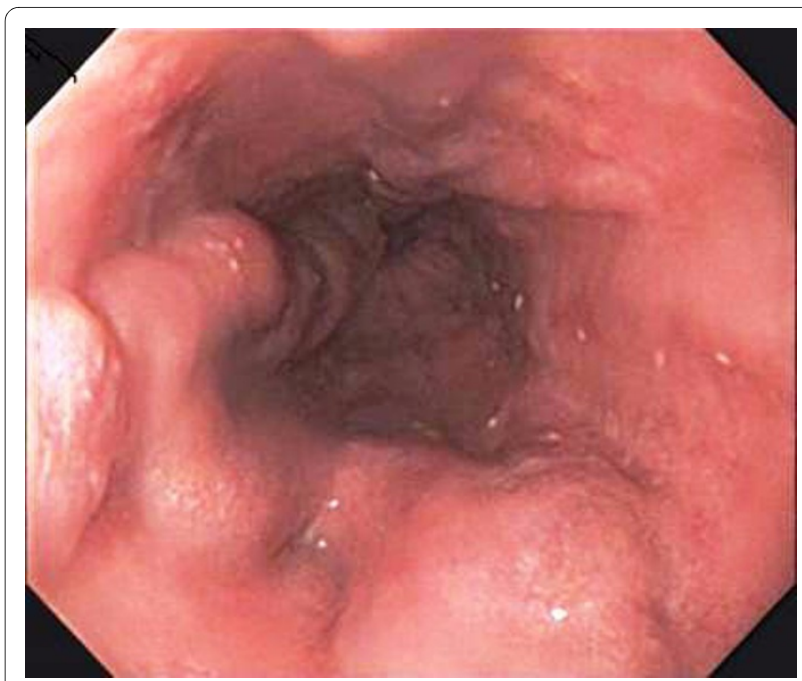

Figure 3 Esophageal varices. (A) The lower esophagus and gastroesophageal junction. (B) The middle esophagus.

The iatrogenic ulcers in the esophagus and EGJ resulting from the EVL were treated with the administration of a proton pump inhibitor and sodium alginate.

The ulcers were observed endoscopically three months after the procedure to check for the presence of any residual lesion or other lesions, and forceps biopsy specimens were obtained from the site of the resection. A follow-up examination after two years did not show recurrence of the disease (Figure 5).

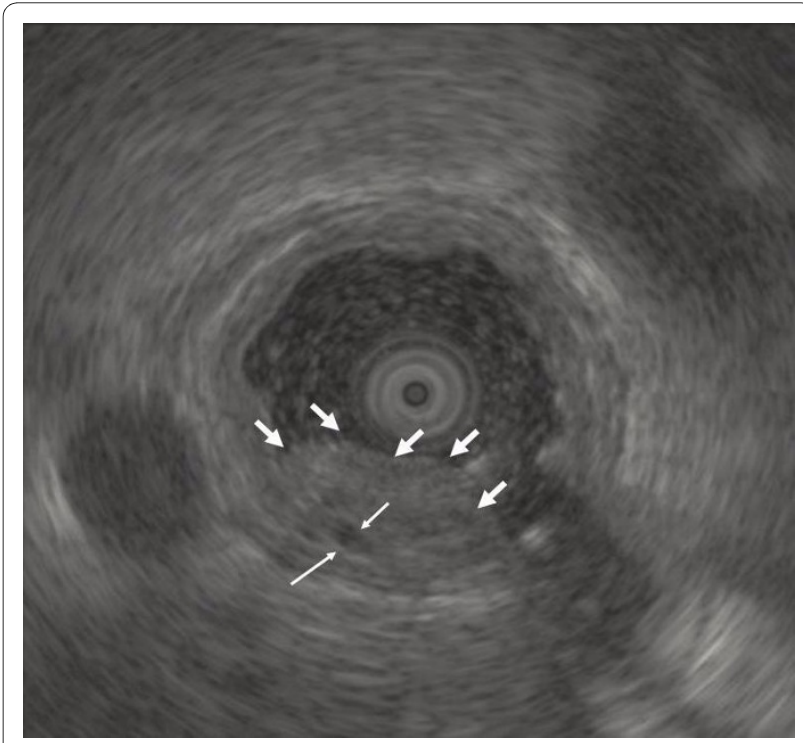

Figure 4 Endoscopic ultrasonography with Olympus UM2000 (Olympus Optical Company, Tokyo, Japan), demonstrates that the minute cancer was noninvasive carcinoma (carcinoma in situ) and a 2-mm diameter blood vessel (thin white arrows), feeding the esophageal varices, pierces the lesion. Thick white thick arrows indicate the minute cancer. 


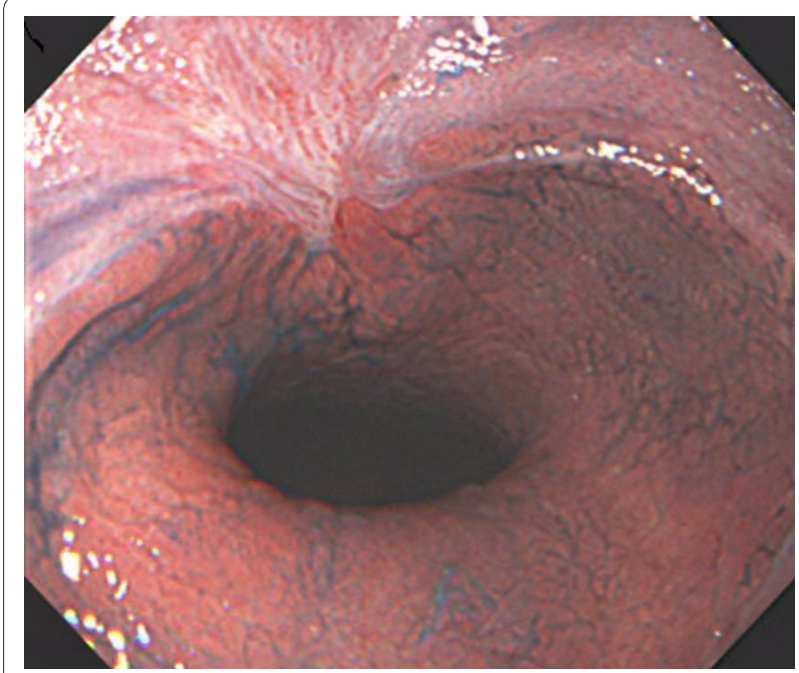

Figure 5 latrogenic ulcer has healed with scarring, but without any residual lesion.

\section{Discussion}

Endoscopic resection has the advantage of providing a full specimen for histological examination and for the diagnosis of the extent and infiltration depth of the lesion. The outcome of endoscopic therapy can therefore be evaluated on the basis of macroscopic and histologic findings. However, in our case, our patient with minute cancer, complicated with esophageal varices, was at a high bleeding risk because of standard endoscopic mucosal resection or endoscopic submucosal dissection. We thus selected endoscopic therapy using EVL, without mucosal resection, for this lesion. This technique had several limitations that may need to be considered. First, large lesions cannot be completely excised with this method because of the size limitation of the friction-fit adaptor. In our case, the diameter of the cancer was less than $10 \mathrm{~mm}$ in diameter. Second, because a full specimen cannot be provided, histological examination and the diagnosis of the extent and infiltration depth of the lesion cannot be evaluated.

\section{Conclusion}

We believe that because of its technical simplicity and safety, endoscopic therapy using an EVL device for minute cancer of the EGJ, complicated with esophageal varices, may be an acceptable and easily applicable method.

\section{Consent}

Written informed consent was obtained from our patient for publication of this case report and any accompanying images. A copy of the written consent is available for review by the Editor-in-Chief of this journal.

\section{Abbreviations}

EGJ: esophagogastric junction; EVL: endoscopic variceal ligation; EUS: endoscopic ultrasonography.

\section{Competing interests}

The authors declare that they have no competing interests.

\section{Authors' contributions}

$\mathrm{TA}, \mathrm{YA}, \mathrm{HT}$ and $\mathrm{KY}$ analyzed and interpreted our patient data. $\mathrm{HI}$, $\mathrm{HE}$ and $\mathrm{KH}$ analyzed endoscopic data. AR, SY and YI performed the histological examination of the organs. TA, MI and AN were major contributors in writing the manuscript. All authors read and approved the final manuscript.

\section{Author Details}

${ }^{1}$ Gastroenterology Division, Yokohama City University School of Medicine, Japan and 2Department of Pathology, Yokohama City University Hospital, Japan

Received: 25 September 2008 Accepted: 23 May 2010

Published: 23 May 2010

\section{References}

1. lishi H, Tatsuta M, Okuda S: Endoscopic diagnosis of minute gastric cancer of less than $5 \mathrm{~mm}$ in diameter. Cancer 1985, 56:655-659.

2. Oohara T, Aono G, Ukawa S, Takezoe K, Johjima Y, Kurosaka H, Asakura R, Tohma H: Clinical diagnosis of minute gastric cancer less than $5 \mathrm{~mm}$ in diameter. Cancer 1984, 53:162-165.

3. Tada M, Murakami A, Karita M, Yanai H, Okita K: Endoscopic resection of early gastric cancer. Endoscopy 1993, 25:445-450.

doi: 10.1186/1752-1947-4-149

Cite this article as: Akiyama et al., Endoscopic therapy using an endoscopic variceal ligation for minute cancer of the esophagogastric junction complicated with esophageal varices: a case report Journal of Medical Case Reports 2010, 4:149

\section{Submit your next manuscript to BioMed Centra} and take full advantage of:

- Convenient online submission

- Thorough peer review

- No space constraints or color figure charges

- Immediate publication on acceptance

- Inclusion in PubMed, CAS, Scopus and Google Scholar

- Research which is freely available for redistribution 